\title{
Inventory and pricing decisions in a single-period problem involving risky supply
}

\author{
Doğan A. Serel * \\ Faculty of Business Administration, Bilkent University, 06800 Bilkent, Ankara, Turkey
}

\section{A R T I C L E I N F O}

\section{Article history:}

Received 25 May 2006

Accepted 16 July 2008

Available online 14 August 2008

\section{Keywords:}

Newsboy

Inventory

Supply uncertainty

Emergency supply

Pricing

\begin{abstract}
A B S T R A C T
We explore an extension of the single-period (newsboy) inventory problem when supply is uncertain. We look into the negotiations between a newsvendor (retailer) and a manufacturer when there is competition from a second supplier. There is a chance that the second supplier will not be able to deliver the product. The retailer can maximize his expected profit by optimally allocating his order between the two suppliers. The retailer's ordering problem is analyzed in conjunction with the manufacturer's related pricing problem. The effects of demand and supply uncertainties on the optimal decisions of the parties are explored using numerical examples. We also explore extension of the retailer's problem to the cases of order cancellation, price-dependent demand, and demand-dependent supply availability.
\end{abstract}

(c) 2008 Elsevier B.V. All rights reserved.

\section{Introduction}

A wide variety of companies carry inventories of finished goods so that they can respond to customer orders without delay. There has been extensive study of the optimal stocking decision in a single-period (newsvendor) problem when demand is uncertain (see, e.g., Khouja, 1999). In the standard newsvendor problem, the buyer tries to balance the costs of shortages and leftovers by determining the most appropriate level of inventory given the demand forecast for the end product and relevant cost parameters (Silver et al., 1998). The newsvendor model can be used to decide on order quantities of style goods and perishable products that should be sold in a single selling season.

While deterministic supply lead time and availability is a fairly common assumption in the inventory literature, there are also models that take into account randomness of product delivery times from suppliers. In some cases, the quantity delivered by a supplier may deviate from the

\footnotetext{
* Tel.: +90312 2902415 ; fax: +90312 2664958.

E-mail address: serel@bilkent.edu.tr
}

quantity ordered by the buyer. Although retailers expect smooth and timely delivery of goods from manufacturers, sometimes supply shortages may result in unsatisfied demand and lost profits for the retailer.

Manufacturers may experience similar problems with their suppliers. Supply failures may be caused by events such as accidents, strikes, and supplier equipment malfunctions (Waller, 2003). Ericsson reported a loss of about $\$ 400$ million in the spring of 2001 ; this was primarily caused by a fire at a supplier's plant that disrupted the supply of radio-frequency chips used in one of Ericsson's key consumer products (Norrman and Jansson, 2004). The financial insolvency of the UK chassis manufacturer UPF Thompson in 2001 threatened the continuity of production at its major customer, Land Rover (Juttner, 2005). Sometimes unexpected surges in demand may temporarily distort the balance between supply and demand. Because of component shortages, Motorola failed to ship the camera phones promised to its major customers during the holiday season in 2003 (Kharif, 2003).

In this paper we develop a single-period inventory model for identifying the best stocking policy for a retailer faced with uncertain demand and supply. We consider a retailer who has two alternative suppliers, one of whom is 
not guaranteed to be available when the retailer needs the product in the future. To reduce his risk, the retailer can purchase any desired amount of the item in advance from the reliable manufacturer, albeit at a higher cost. We focus on the rational actions of the retailer and the manufacturer in this dual supplier environment. Within a single-period inventory framework, we analyze the joint impact of demand and supply uncertainties on the optimal decisions (order quantity and supply price) of the parties. We also look into changes in the retailer's optimal ordering policy in different scenarios involving backordered demand, order cancellation flexibility, pricesensitive demand, and supply availability correlated with demand. Since the newsvendor model with a linear supply price is applicable in a wide range of business settings, our analytical approach can be used to explore various aspects of the retailer-manufacturer relationship under conditions of supply uncertainty. In our numerical study we find that the optimal price for the reliable manufacturer does not change much regardless of whether the retailer orders from the risky supplier prior to or after observing the random demand.

Retailers can guarantee the availability of supplies by placing their purchase orders with a reliable manufacturer long before the start of the selling season. If certain manufacturers in the market are more reliable than others and more in demand, buyers may be compelled to make early purchase commitments to procure the product from the reliable manufacturers. In some other cases, existing constraints on supply capacity prompt retailers to make early commitments. Backup agreements between retailers and manufacturers are an example of the advance purchase commitment that we study in this paper. In backup agreements with a manufacturer of fashion garments, a retailer orders in two stages: the initial firm order is delivered before the start of the season, and later additional units can be ordered from a backup during the season (Eppen and Iyer, 1997). In our model, the backup is unreliable, and becomes unavailable when the selling season starts. Advance supply commitments also benefit the manufacturers through improved production planning, and potential cost savings in the procurement of raw materials.

Supply uncertainty has been incorporated into stochastic demand inventory models in various ways in the literature. The papers can be further categorized into single-supplier and multiple-supplier models. Single-supplier models are primarily concerned with the determination of optimal inventory control policy given imperfect supply. Some authors have considered random supply capacity in a periodic review inventory control framework (Ciarallo et al., 1994; Erdem and Ozekici, 2002). There are also all-or-none models which assume that supply availability is described by a Bernoulli process each period (Parlar et al., 1995; Ozekici and Parlar, 1999; Gullu et al., 1999); there is a certain probability that the quantity ordered by the buyer is fully received, or no delivery occurs. Another approach is to assume that the supplier becomes unavailable to the buyer for a random duration followed by an interval of availability of random length (Parlar, 1997; Mohebbi, 2004; Mohebbi and Hao, 2006). In the yield uncertainty case, it is assumed that the supplier delivers a random fraction of the order placed by the buyer (Wang and Gerchak, 1996; Inderfurth, 2008; AbdelMalek et al., 2008).

The multiple-supplier models in the literature address the issues of supplier selection and optimal-order allocation. Papers in this category include models in which supply uncertainty is specified as random capacity (Erdem et al., 2006), all-or-none supply availability (Dada et al., 2007; Babich et al., 2007), on and off times with random durations (Gurler and Parlar, 1997), and random yield (Agrawal and Nahmias, 1997; Yang et al., 2007). Minner (2003) reviews the research in multiple-supplier inventory models.

In this paper, we use the all-or-none supply availability approach to model the uncertainty about supply. The retailer's problem in our work to some extent resembles the single-period ordering problem studied by Jain and Silver (1995) where a supplier with a random supply capacity guarantees availability at a premium price. The retailer's problem in Jain and Silver (1995) is to decide the order size, and the portion of the order size to be designated as the dedicated capacity. The availability of the dedicated capacity is certain; however, the supplier's realized capacity may not be enough to fully meet the remaining part of the retailer's order. In our paper, the supply uncertainty is specified differently, and there are two different suppliers.

The key contributions of the paper can be summarized as follows. (1) We extend the single-period inventory problem with supply uncertainty to the case where the supply price is determined within the framework of a Stackelberg game. (2) In addition to the buyer's inventory problem, we also analyze the structural properties of the supplier's pricing problem in a single-period setting. The buyer's inventory problem in conditions of supply uncertainty has been investigated by a number of researchers, but they have not fully explored the supplier's perspective in this environment. We identify the conditions that ensure unimodality of the supplier's profit function. (3) We study the pricing competition between a reliable supplier and a risky supplier for a newsvendor, and explore the conditions for the existence and uniqueness of Nash equilibrium in this competition. (4) We also generalize the newsvendor model with a deterministic emergency supply option studied in the literature; we investigate the case where emergency supply is randomly available to the newsvendor. (5) Finally, we propose a model integrating the case of supply uncertainty with price-dependent demand within a single-period framework.

\section{Model}

We focus on the interaction between a retailer and a manufacturer when there is a second source of supply from which the retailer can fill some or all of his stocking needs. The product is resold by the retailer to his customers at retail price, $p$. We assume a Bernoulli probability distribution for availability of the second 
source to the retailer in the future. As noted earlier, supply disruptions may be caused by a variety of factors in practice; we refer to the second source as the "risky supplier". The probability that the retailer will be able to purchase any amount he wants from the risky supplier is $u$, and the probability is $1-u$ that no amount of product will be available from the risky supplier for immediate delivery.

The retailer's ordering plan may involve dividing his total order into two parts such that $R$ units will be obtained from the manufacturer, and $S-R$ units will be ordered later from the risky supplier (if available). Depending on the relative costs of sourcing from the manufacturer and the risky supplier, the retailer can also decide to use one of these two sources of supply exclusively. We remark that the risky supplier may correspond to a spot market. The problem of allocating a buyer's procurement orders among a preferred supplier and a reliable spot market was previously studied in Serel et al. (2001) within a multi-period framework; the extension to the unreliable spot market case was examined in Serel (2007).

Let $\pi$ denote the shortage cost (loss of goodwill), and $\tau$ denote the unit salvage value of leftovers at the end of the season. We use $c_{2}$ and $c$ to represent the wholesale price per unit charged by the risky supplier and the manufacturer, respectively. The price of the risky supplier, $c_{2}$, is exogenous to the model; but the manufacturer's supply price $c$ is to be determined based on negotiations between the retailer and the manufacturer. To eliminate unrealistic cases, we assume $c, c_{2}<p$. We also let $c_{s}$ be the unit production cost of the manufacturer.

The cumulative distribution function (cdf) of demand faced by the retailer is denoted as $F(x)$, the mean demand is $\mu$, the standard deviation of the demand distribution is $\sigma$, the complementary cdf is $F_{c}(x)$, and the probability density function (pdf) of demand is $f(x)$.

We study a Stackelberg game between the retailer and the manufacturer in which the manufacturer determines her wholesale price $c$ based on the expected reaction of the retailer to this price. As $c$ increases, the retailer will decrease his order amount from the manufacturer $(R)$; there will thus be an optimal price $c^{*}$ that maximizes the manufacturer's expected profit. We show that under certain restrictions on the probability of risky-supplier availability, $u$, and the demand distribution class, the manufacturer's profit will be a quasi-concave function of $c$.

Our paper is structured as follows. First, we formulate the retailer's problem, and derive his optimal inventory decision. Then, we analyze the manufacturer's pricing problem. The issue of Nash equilibrium in the pricing game between the manufacturer and the risky supplier is addressed in Section 3. Subsequently, in Section 4 we consider a variant of the problem where the retailer starts the selling season with inventory supplied by the manufacturer only. If observed demand exceeds the stock on hand at the beginning of the season, extra units from the risky supplier are ordered (if available). This variant of the problem is similar to the newsvendor problem with an emergency supply option (Gallego and Moon, 1993; Khouja, 1996); the difference in our case is that avail- ability of emergency supply is not certain but subject to the outcome of a Bernoulli process. Next, we consider various extensions of the retailer's ordering problem including the scenario where demand for the product depends on the selling price. Following numerical examples, we offer some concluding remarks.

\section{Optimal policies of the retailer and the manufacturer when excess demand is lost}

In this section we first study the retailer's problem assuming that supply prices are given. Subsequently we analyze the manufacturer's optimal pricing decision, taking into account the expected response of the retailer to this price.

\subsection{The retailer's ordering policy}

The retailer's optimal ordering policy follows one of three paths: using the manufacturer only, using the risky supplier only, and using both sources. Since we are interested in the cases in which the manufacturer has a nonzero share of the retailer's total order amount, we first write the retailer's objective function based on the assumption that the retailer uses both sources of supply. If the optimal $R=0$, this will correspond to the case in which the retailer includes only the risky supplier in his ordering plan.

The retailer's expected profit as a function of $R$ and $S$, $B(R, S)$, can be written as

$$
\begin{aligned}
B(R, S)= & (1-u)\left\{p \mathrm{E}[\min (R, X)]+\tau E(R-X)^{+}\right. \\
& \left.-\pi \mathrm{E}(X-R)^{+}-c R\right\} \\
& +u\left\{p \mathrm{E}[\min (S, X)]+\tau \mathrm{E}(S-X)^{+}\right. \\
& \left.-\pi \mathrm{E}(X-S)^{+}-c_{2}(S-R)-c R\right\},
\end{aligned}
$$

where $X$ is the random demand, and $(W)^{+} \equiv \max (W, 0)$. With probability $1-u$, the retailer will start the season with $R$ units on hand; with probability $u$, the starting inventory will be $S$. The retailer's expected profit function is composed of four parts: expected revenue, salvage value, shortage penalty, and purchase cost. Note that the retailer orders $R$ units from the manufacturer before observing availability of the risky supplier. The partial derivatives of $\mathrm{B}(R, S)$ are

$\partial B / \partial R=(1-u)\left[(p+\pi) F_{c}(R)+\tau F(R)-c\right]+u\left(c_{2}-c\right)$,

$\partial B / \partial S=u\left[(p+\pi) F_{c}(S)+\tau F(S)-c_{2}\right]$.

The second partial derivatives of $B(R, S)$ are

$\partial^{2} B / \partial R^{2}=-(1-u)[(p+\pi-\tau) f(R)]<0$,

$\partial^{2} B / \partial S^{2}=-u[(p+\pi-\tau) f(S)]<0$.

The retailer needs to solve the following optimization problem:

Maximize $B(R, S)$

subject to $0 \leqslant R \leqslant S$.

Since $\mathrm{B}(R, S)$ is jointly concave in $R$ and $S$, the optimal solution can be found using Karush-Kuhn-Tucker (KKT) 
conditions. Let $\lambda$ and $v$ be the Lagrange multipliers. The KKT conditions are

$\partial B / \partial R=\lambda-v, \quad \partial B / \partial S=-\lambda$,

$\lambda(R-S)=0, \quad v R=0, \quad \lambda, v \geqslant 0$.

Setting the first partial derivatives (2) and (3) equal to zero, we obtain

$F(R)=\left[(1-u)(p+\pi-c)+u\left(c_{2}-c\right)\right] /[(1-u)(p+\pi-\tau)]$,

$F(S)=\left(p+\pi-c_{2}\right) /(p+\pi-\tau)$.

Higher $u$ corresponds to lower supply uncertainty for the retailer. Observe that the total order amount $S$ does not depend on $u$; that is, the degree of supply uncertainty has no impact on the total quantity that the retailer plans to order. From the monotonocity of $F(\cdot)$, if $F(R)<F(S)$, then $R<S$. The values of $R$ and $S$ given by (4) and (5) satisfy the constraint $R \leqslant S$ when

$$
\begin{aligned}
& {\left[(1-u)(p+\pi-c)+u\left(c_{2}-c\right)\right] /[(1-u)(p+\pi-\tau)]} \\
& \quad \leqslant\left(p+\pi-c_{2}\right) /(p+\pi-\tau) .
\end{aligned}
$$

Inequality (6) implies that $c \geqslant c_{2}$. By (4), when $c \geqslant c_{2}$, as $u$ increases, $R$ decreases. On the other hand, $R$ given by ( 4$)$ is zero when $c \geqslant c_{\max }=(1-u)(p+\pi)+u c_{2}$. Thus, the retailer will order from both sources when $c_{2}<c<c_{\max }$. In other words, the retailer will decide how to divide his order between a reliable and high-cost supplier, and an unreliable and low-cost supplier. The upper limit on the wholesale price, $c_{\max }$, increases as the probability of risky-supplier availability $u$ decreases. For $u=0, c_{\max }=$ $p+\pi$. For $u=1, c_{\max }=c_{2}$, meaning that when the availability of the second supplier is certain, the manufacturer has to set her price below $c_{2}$ to be able to sell to the retailer.

If $c \geqslant c_{\max }, R=0$ and only the risky supplier will be used. Note that when $R=0$, the optimal amount that the retailer plans to order, $S$, will still be given by (5). If $c \leqslant c_{2}$, then optimal $R$ will be equal to optimal $S$, and only the manufacturer will receive a positive order from the retailer. If $R=S$, KKT conditions give

$\partial B / \partial R+\partial B / \partial S=0$.

Setting $R=S$, and substituting (2) and (3) in (7), we obtain

$F(R)=(p+\pi-c) /(p+\pi-\tau)$.

Eq. (8) describes the solution to the traditional singlesupplier newsvendor problem with supply price $c$. The retailer's expected profit is expressed as $B(R)$ in this case since $R$ is the only variable.

If only the risky supplier is available to the retailer (with probability $u$ ), the retailer's expected profit can be written as

$$
\begin{aligned}
B(S)= & -(1-u) \pi \mu+u\left\{p \mathrm{E}[\min (S, X)]+\tau E(S-X)^{+}\right. \\
& \left.-\pi E(X-S)^{+}-c_{2} S\right\} .
\end{aligned}
$$

The value of $S$ maximizing (9) is given by (5). Hence, independent of the value of $u$, if the risky supplier is available, the retailer will stock the constant $S$ units, and nothing else.
To recap, the retailer's optimal ordering policy has 3 possible scenarios: for $c \leqslant c_{2}$, the retailer uses only the manufacturer; if $c_{2}<c<c_{\max }$, the retailer orders from both the manufacturer and the risky supplier, and if $c \geqslant c_{\max }$, the risky supplier will be the sole source of supply.

Although we have assumed a fixed probability of availability $u$, our model is actually more general, and our results also hold when the parameter $u$ itself is uncertain. Let $w(u)$ be the pdf of the random variable $U$ which can take values in the interval between 0 and 1 . Assuming that probability of availability of the risky supplier and demand for the product are independent of each other, we can write the retailer's expected profit as

$$
\begin{aligned}
B(R, S) & =\int_{0}^{1}\left[(1-u) T_{1}(R)+u T_{2}(R, S)\right] w(u) \mathrm{d} u \\
& =[1-\mathrm{E}(U)] T_{1}(R)+E(U) T_{2}(R, S),
\end{aligned}
$$

where $T_{1}(R)$ is the term inside the first \{\} on the righthand side (RHS) of (1), and $T_{2}(R, S)$ is the term inside the second \{\} on the RHS of (1). When we have uncertainty in the availability parameter, the term $u$ in our analysis can be interpreted as the expected value of that parameter. Hence, all our results will also apply in the case of a random Bernoulli parameter.

\subsection{The manufacturer's pricing decision}

In order to maximize her profit, the manufacturer needs to determine her optimal wholesale price based on the expected response of the retailer to her choice of $c$. Knowing the functional relationship between $c$ and the retailer's order quantity (as derived in the previous subsection), the manufacturer solves two optimization problems:

(I) Maximize $M_{1}(c)=\left(c-c_{s}\right) R$

$$
\begin{array}{ll}
\text { subject to } & F(R)=(p+\pi-c) /(p+\pi-\tau), \\
& c \leqslant c_{2}, \\
& B(R) \geqslant 0 .
\end{array}
$$

(II) Maximize $M_{2}(c)=\left(c-c_{s}\right) R$

$$
\begin{array}{ll}
\text { subject to } & F(R)=\frac{(1-u)(p+\pi-c)+u\left(c_{2}-c\right)}{(1-u)(p+\pi-\tau)}, \\
& c_{2}<c<c_{\max }, \\
& B(R, S) \geqslant 0 .
\end{array}
$$

Whether the optimal $c$ is less than or more than $c_{2}$ depends on the closeness of $c_{2}$ to the selling price $p$. If $c_{2}$ is low enough, the optimal $c$ will fall in the interval between $c_{2}$ and $c_{\max }$. The task of finding the optimal price for the manufacturer would be greatly simplified if $M_{1}$ and $M_{2}$ were unimodal functions of $c$. In Proposition 1 , we show that $M_{1}$ is quasi-concave in $c$ if the demand distribution belongs to the large class of increasing generalized failure rate (IGFR) distributions (Lariviere and Porteus, 2001). For distributions in this class, the 
generalized failure rate $g(x)=f(x) x / F_{c}(x)$ is an increasing function of $x$.

Proposition 1. The manufacturer's profit function when the retailer sources only from the manufacturer, $M_{1}$, is quasiconcave in $c$ if the demand distribution is IGFR.

Proof. First note that from expression (8) for $F(R)$, we have

$\partial R / \partial c=-[(p+\pi-\tau) f(R)]^{-1}<0$,

$F_{c}(R)=1-F(R)=(c-\tau) /(p+\pi-\tau)$.

From (11),

$c=(p+\pi-\tau) F_{c}(R)+\tau$.

The first derivative of $M_{1}$ with respect to $c$ is

$\mathrm{d} M_{1} / \mathrm{d} c=R+\left(c-c_{S}\right) \partial R / \partial c$.

Substituting (10) and (12) in (13),

$\frac{\mathrm{d} M_{1}}{\mathrm{~d} c}=R\left[1-\frac{F_{c}(R)}{f(R) R}\right]+\left[\frac{c_{s}-\tau}{(p+\pi-\tau) f(R)}\right]$.

We assume $\tau<c_{s}$ since the case $\tau>c_{s}$ indicates riskless profit for the manufacturer. Hence, when $\mathrm{d} M_{1} / \mathrm{d} c=0$, we have

$F_{c}(R)>f(R) R$

and by (13)

$c-c_{s}=-R /(\partial R / \partial c)$.

The second derivative of $M_{1}$ with respect to $c$ is

$\frac{\mathrm{d}^{2} M_{1}}{\mathrm{~d} c^{2}}=\frac{\mathrm{d} R}{\mathrm{~d} c}\left\{2+\frac{\left(c-c_{s}\right)}{(p+\pi-\tau)[f(R)]^{2}} \frac{\mathrm{d} f(R)}{\mathrm{d} R}\right\}$.

Combining (10), (16), and (17), at $\mathrm{d} M_{1} / \mathrm{d} c=0$, we have

$\frac{\mathrm{d}^{2} M_{1}}{\mathrm{~d} c^{2}}=\frac{\mathrm{d} R}{\mathrm{~d} c}\left[2+\frac{R}{f(R)} \frac{\mathrm{d} f(R)}{\mathrm{d} R}\right]$

Note that

$2+\frac{R}{f(R)} \frac{\mathrm{d} f(R)}{\mathrm{d} R}=\frac{f(R)+(\mathrm{d} f(R) / \mathrm{d} R) R+f(R)}{f(R)}$.

Eqs. (15) and (19) imply that

$2+\frac{R}{f(R)} \frac{\mathrm{d} f(R)}{\mathrm{d} R}>\frac{F_{c}(R)(\mathrm{d} g(R) / \mathrm{d} R)}{f(R)}$.

Finally, using $\operatorname{dg}(R) / \mathrm{d} R \geqslant 0$ and $\mathrm{d} R / \mathrm{d} c<0$, we conclude that $\mathrm{d}^{2} M_{1} / \mathrm{d} c^{2} \leqslant 0$ when $\mathrm{d} M_{1} / \mathrm{d} c=0$, and consequently $M_{1}(c)$ is quasi-concave in $c$.

The quasi-concavity of $M_{2}$ with respect to $c$ is guaranteed under an additional condition on the value of $c_{s}$, which is stated in Proposition 2.

Proposition 2. The manufacturer's profit function when the retailer plans to use both the manufacturer and the risky supplier, $M_{2}$, is quasi-concave in $c$ if the demand distribution is IGFR and $c_{s}>(1-u) \tau+u c_{2}$.

Proof. Observe that from (4)

$\partial R / \partial c=-[(1-u)(p+\pi-\tau) f(R)]^{-1}<0$.
Using (21),

$$
\begin{aligned}
\frac{\mathrm{d} M_{2}}{\mathrm{~d} c} & =R+\left(c-c_{s}\right) \frac{\partial R}{\partial c} \\
& =R\left[1-\frac{c}{(1-u)(p+\pi-\tau) f(R) R}\right]+\frac{c_{s}}{(1-u)(p+\pi-\tau) f(R)} .
\end{aligned}
$$

Combining (4) and (22),

$\frac{\mathrm{d} M_{2}}{\mathrm{~d} c}=R\left[1-\frac{F_{c}(R)}{f(R) R}\right]+\frac{-\tau(1-u)-u c_{2}+c_{s}}{(1-u)(p+\pi-\tau) f(R)}$

If $c_{s}>(1-u) \tau+u c_{2}$, then at $\mathrm{d} M_{2} / \mathrm{d} c=0, F_{c}(R)>f(R) R$. The second derivative of $M_{2}$ with respect to $c$ is

$\frac{\mathrm{d}^{2} M_{2}}{\mathrm{~d} c^{2}}=\frac{\mathrm{d} R}{\mathrm{~d} c}\left\{2+\frac{\left(c-c_{s}\right)}{(1-u)(p+\pi-\tau)[f(R)]^{2}} \frac{\mathrm{d} f(R)}{\mathrm{d} R}\right\}$.

At $\mathrm{d} M_{2} / \mathrm{d} c=0$, the second derivative equals

$\frac{\mathrm{d}^{2} M_{2}}{\mathrm{~d} c^{2}}=\frac{\mathrm{d} R}{\mathrm{dc}}\left[2+\frac{R}{f(R)} \frac{\mathrm{d} f(R)}{\mathrm{d} R}\right]$

Following steps similar to Proposition 1, it can be shown that $\mathrm{d}^{2} M_{2} / \mathrm{d} c^{2} \leqslant 0$ when $\mathrm{d} M_{2} / \mathrm{d} c=0$.

According to Proposition 2, if the manufacturer's unit production cost $c_{s}$ is greater than a lower bound, $\mathrm{LB}=(1-u) \tau+u c_{2}, M_{2}$ will be a quasi-concave function of $c$; LB is actually a weighted average of the salvage value $\tau$ and $c_{2}$. If $u=0, \mathrm{LB}=\tau$, and the condition reduces to $c_{s}>\tau$. As $u$ increases LB increases, and the condition $c_{s}>\mathrm{LB}$ becomes more restrictive. Nonetheless, when the problem parameters ensure that both $M_{1}$ and $M_{2}$ are quasi-concave in $c$, the solution to the manufacturer's pricing problem can be easily determined. The quasi-concavity condition for $M_{2}$ can also be expressed as $u<\left(c_{s}-\tau\right) /\left(c_{2}-\tau\right)$.

Let $a^{(1)}$ and $a^{(2)}$ be the prices satisfying the first-order conditions $\mathrm{d} M_{1} / \mathrm{d} c=0$ and $\mathrm{d} M_{2} / \mathrm{d} c=0$ in optimization problems (I) and (II), respectively. Given that $M_{1}$ and $M_{2}$ are quasi-concave, the manufacturer's optimal profit, $M^{*}$,

Table 1

Manufacturer's optimal profit, $M^{*}$, when both $M_{1}$ and $M_{2}$ are quasiconcave

\begin{tabular}{ll}
\hline Case & $M^{*}$ \\
\hline$a^{(1)} \leqslant c_{2}, a^{(2)}<c_{2}$ & $M_{1}\left(a^{(1)}\right)$ \\
$a^{(1)}>c_{2}, a^{(2)}<c_{2}$ & $M_{1}\left(c_{2}\right)=M_{2}\left(c_{2}\right)$ \\
$a^{(1)}>c_{2}, a^{(2)} \geqslant c_{2}$ & $M_{2}\left(a^{(2)}\right)$ \\
\hline
\end{tabular}

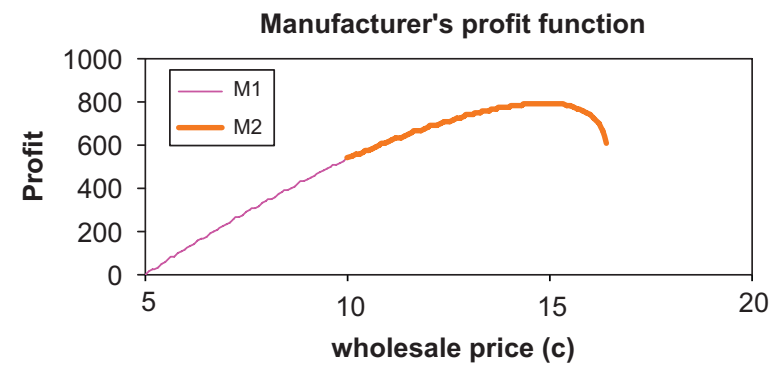

Fig. 1. Manufacturer's profit functions $M_{1}(c)$ and $M_{2}(c)$ in the lost sales model $\left(c_{2}=10, c^{*}=a^{(2)}=14.9\right)$ 
is as shown in Table 1. Using a numerical example with $c_{2}=10, M_{1}$ and $M_{2}$ are plotted against $c$ in Fig. 1 . In this example, the third case in Table 1 holds; the manufacturer's optimal price $c^{*}=a^{(2)}=14.9$, and the maximum profit $M^{*}=M_{2}(14.9)=\$ 793.1$.

We can derive an expression for $a^{(1)}$ by solving

$\mathrm{d} M_{1} / \mathrm{d} c=R+\left(c-c_{s}\right) \partial R / \partial c=0$,

where $R$ is given by (8). From (26), we obtain

$a^{(1)}=c_{s}+R(p+\pi-\tau) f(R)$.

Hence, if $a^{(1)}$ is the optimal wholesale price for the manufacturer, the optimal markup amount over the production cost is $R(p+\pi-\tau) f(R)$. Since $R$ is a function of $c$, the value of $a^{(1)}$ must be found by solving the zero of a nonlinear equation. By substituting the value of $a^{(1)}$ in $M_{1}$,

$M_{1}\left(a^{(1)}\right)=\left(a^{(1)}-c_{s}\right) R=R^{2}(p+\pi-\tau) f(R)$.

Similarly, by solving

$\mathrm{d} M_{2} / \mathrm{d} c=R+\left(c-c_{s}\right) \partial R / \partial c=0$,

we find

$a^{(2)}=c_{s}+R(1-u)(p+\pi-\tau) f(R)$,

where $R$ is given by (4). It also follows that

$M_{2}\left(a^{(2)}\right)=\left(a^{(2)}-c_{s}\right) R=R^{2}(1-u)(p+\pi-\tau) f(R)$.

In Proposition 3, we explore the behavior of the manufacturer's profit in response to changes in supply uncertainty.

Proposition 3. The manufacturer's optimal profit is a nonincreasing function of the probability of risky-supplier availability $u$ if the demand distribution is IGFR and $c_{s}>(1-u) \tau+u c_{2}$.

Proof. Since $R$ does not depend on $u$ when $c=c_{2}$, $\mathrm{d} M_{1}\left(c_{2}\right) / \mathrm{d} u=\mathrm{d} M_{2}\left(c_{2}\right) / \mathrm{d} u=0$. Also, because $R$ given by (8) does not depend on $u, \mathrm{~d} M_{1}\left(a^{(1)}\right) / \mathrm{d} u=0$. Using (4),

$\mathrm{d} R / \mathrm{d} u=\left(c_{2}-c\right)(1-u)^{-2}[(p+\pi-\tau) f(R)]^{-1}<0$.

We can rewrite (29) as

$M_{2}\left(a^{(2)}\right)=\left[f(R) / F_{c}(R)\right] R^{2}\left[-(1-u) \tau+c-u c_{2}\right]$.

Substituting $g(R)=\left[f(R) R / F_{c}(R)\right]$, and differentiating (31),

$$
\begin{aligned}
\frac{\mathrm{d} M_{2}\left(a^{(2)}\right)}{\mathrm{d} u}= & {\left[-(1-u) \tau+c-u c_{2}\right] } \\
& \times \frac{\partial R}{\partial u}\left[R \frac{\partial g(R)}{\partial R}+g(R)\right]+\left(\tau-c_{2}\right) g(R) R \leqslant 0 .
\end{aligned}
$$

Inequality (32) holds because of (30), and $\tau<c_{2}$. The IGFR assumption implies that $\partial g(R) / \partial R>0$. Thus, the manufacturer's optimal profit is inversely related to $u$.

The impacts of other parameters on the manufacturer's optimal profit are investigated using numerical examples in a later section. We can examine the relationship between the optimal wholesale price and supply uncertainty by evaluating $\mathrm{d} c^{*} / \mathrm{d} u$. Since $R$ does not depend on $u$ when $c^{*} \in\left\{a^{(1)}, c_{2}\right\}$, we focus on the behavior of $c^{*}=a^{(2)}$. We can rewrite $(28)$ as

$a^{(2)}=c_{s}+\left[-(1-u) \tau+c-u c_{2}\right] g(R)$.
Differentiating (33):

$\frac{\mathrm{d} a^{(2)}}{\mathrm{d} u}=\left[-(1-u) \tau+c-u c_{2}\right] \frac{\partial g(R)}{\partial R} \frac{\partial R}{\partial u}+g(R)\left(\tau-c_{2}\right) \leqslant 0$

Since $\partial R / \partial u<0$, and $\tau<c_{2}, c^{*}$ is a nonincreasing function of the probability of risky-supplier availability $u$ if the demand distribution is IGFR and $c_{s}>(1-u) \tau+u c_{2}$.

\subsection{The risky supplier's pricing decision and Nash equilibrium}

Although so far we have assumed that the risky supplier's price $c_{2}$ is given, as pointed out by a referee, it may be interesting to relax this assumption and investigate whether there exists a Nash equilibrium if both the manufacturer and the risky supplier set their prices simultaneously in a static non-cooperative game scenario. Given $c$, and assuming that the unit production cost of the risky supplier is $c_{s 2}, \tau<c_{s 2}<c_{2}$, the risky supplier's problem can be written as

(III) Maximize $R S_{1}\left(c_{2}\right)=\left(c_{2}-c_{s 2}\right) S$

$$
\begin{array}{ll}
\text { subject to } & F(S)=\left(p+\pi-c_{2}\right) /(p+\pi-\tau), \\
& c \geqslant c_{\max }=(1-u)(p+\pi)+u c_{2}, \\
& B(S) \geqslant 0 .
\end{array}
$$

(IV) Maximize $R S_{2}\left(c_{2}\right)=\left(c_{2}-c_{s 2}\right)(S-R)$

$$
\begin{array}{ll}
\text { subject to } & F(R)=\frac{(1-u)(p+\pi-c)+u\left(c_{2}-c\right)}{(1-u)(p+\pi-\tau)}, \\
& F(S)=\left(p+\pi-c_{2}\right) /(p+\pi-\tau), \\
& c_{2}<c<c_{\max }, \\
& B(R, S) \geqslant 0 .
\end{array}
$$

In a similar manner to Proposition 1 , it can be shown that the risky supplier's profit function $R S_{1}\left(c_{2}\right)$ is quasiconcave in $c_{2}$ if the demand distribution is IGFR. Since the retailer orders from both the manufacturer and the risky supplier when $c_{2}<c<c_{\max }$, we focus on that case (Problem IV). Note that the best response of the risky supplier to any manufacturer price $c$ is to offer a price below $c$. The existence of Nash equilibrium can be shown using different approaches. In Proposition 4, we show that, under certain conditions, the manufacturer's (risky supplier's) profit function is quasi-concave in the decision $c\left(c_{2}\right)$, which implies that there is at least one Nash equilibrium in the pricing game between the manufacturer and the risky supplier (Cachon and Netessine, 2004). In this subsection, we assume that the demand distribution is an increasing failure rate (IFR) distribution, i.e. the failure rate $f(x) / F_{c}(x)$ is an increasing function of $x$. The IFR distributions belong to the larger IGFR class, and the set of IFR distributions includes commonly used distributions such as normal and gamma distributions.

Proposition 4. There exists at least one Nash equilibrium in the non-cooperative game played between the manufacturer and the risky supplier if the demand distribution is IFR, $u<\left(c_{s}-\tau\right) /\left(c_{2}-\tau\right)$, and $\partial f(R) / \partial R \leqslant 0$. 
Proof. First consider the manufacturer's profit function. Since IGFR implies IFR, from Proposition $2, M_{2}$ is quasiconcave in $c$ if the demand distribution is IFR, and $u<\left(c_{s}-\tau\right) /\left(c_{2}-\tau\right)$; in fact, it can be shown that $M_{2}$ is concave in $c$ under these two assumptions.

Consider now the risky supplier's payoff. Note that

$\frac{\partial R S_{2}}{\partial c_{2}}=S-R+\left(c_{2}-c_{s 2}\right)\left(\frac{\partial S}{\partial c_{2}}-\frac{\partial R}{\partial c_{2}}\right)$.

From (4),

$\partial R / \partial c_{2}=u[(1-u)(p+\pi-\tau) f(R)]^{-1}>0$,

$\frac{\partial^{2} R}{\partial c_{2}^{2}}=\frac{-u}{(1-u)(p+\pi-\tau)[f(R)]^{2}} \frac{\partial f(R)}{\partial R} \frac{\partial R}{\partial c_{2}}$.

From (5),

$\partial S / \partial c_{2}=-[(p+\pi-\tau) f(S)]^{-1}<0$,

$\frac{\partial^{2} S}{\partial c_{2}^{2}}=\frac{1}{(p+\pi-\tau)[f(S)]^{2}} \frac{\partial f(S)}{\partial S} \frac{\partial S}{\partial c_{2}}$.

Differentiating (34),

$\frac{\partial^{2} R S_{2}}{\partial c_{2}^{2}}=2\left(\frac{\partial S}{\partial c_{2}}-\frac{\partial R}{\partial c_{2}}\right)+\left(c_{2}-c_{s 2}\right)\left(\frac{\partial^{2} S}{\partial c_{2}^{2}}-\frac{\partial^{2} R}{\partial c_{2}^{2}}\right)$.

Substituting (38) into (39),

$$
\begin{aligned}
\frac{\partial^{2} R S_{2}}{\partial c_{2}^{2}}= & \frac{\partial S}{\partial c_{2}}\left[2+\frac{\left(c_{2}-c_{s 2}\right)}{(p+\pi-\tau)[f(S)]^{2}} \frac{\partial f(S)}{\partial S}\right] \\
& -2 \frac{\partial R}{\partial c_{2}}-\left(c_{2}-c_{s 2}\right) \frac{\partial^{2} R}{\partial c_{2}^{2}}
\end{aligned}
$$

Using the IFR property,

$K_{1} \equiv-\left\{\frac{F_{c}(S)}{[f(S)]^{2}} \frac{\partial f(S)}{\partial S}\right\}=-\left\{\frac{c_{2}-\tau}{(p+\pi-\tau)[f(S)]^{2}} \frac{\partial f(S)}{\partial S}\right\}<1$,

Substituting (41) into (40),

$\frac{\partial^{2} R S_{2}}{\partial c_{2}^{2}}=\frac{\partial S}{\partial c_{2}}\left[2-\frac{\left(c_{2}-c_{s 2}\right) K_{1}}{\left(c_{2}-\tau\right)}\right]-2 \frac{\partial R}{\partial c_{2}}-\left(c_{2}-c_{s 2}\right) \frac{\partial^{2} R}{\partial c_{2}^{2}}$.

If $K_{1}<0$, the term $2-\left(c_{2}-c_{s 2}\right) K_{1} /\left(c_{2}-\tau\right)$ is positive since $c_{2}>c_{s 2}$, and the denominator $\left(c_{2}-\tau\right)>0$. If $0 \leqslant K_{1}<1$, and $\left(c_{2}-c_{s 2}\right) /\left(c_{2}-\tau\right)<1$, the term $2-\left(c_{2}-c_{s 2}\right) K_{1} /\left(c_{2}-\tau\right)$ will be positive. Since $c_{s 2}>\tau$, the term $2-\left(c_{2}-c_{s 2}\right) K_{1} /\left(c_{2}-\tau\right)$ is positive. Using (35) and (37), we find that if $\partial^{2} R / \partial c_{2}^{2} \geqslant 0$ and $\tau<c_{s 2}, \partial^{2} R S_{2} / \partial c_{2}^{2} \leqslant 0$. By (35) and (36), $\partial^{2} R / \partial c_{2}^{2} \geqslant 0$ if $\partial f(R) / \partial R \leqslant 0$. Thus $R S_{2}\left(c_{2}\right)$ is concave in $c_{2}$ if the demand distribution is IFR and $\partial f(R) / \partial R \leqslant 0$.

The condition $\partial f(R) / \partial R \leqslant 0$ is met by the uniform and exponential distribution. If the demand distribution is normal, this condition implies that $F(R)$ should be greater than 0.5 . We remark that a similar condition is imposed on the demand density for proving the existence of Nash equilibrium in the two-supplier competition model of Sethi et al. (2005).
With additional conditions on the demand distribution, it can be shown that there is a unique Nash equilibrium. To show the uniqueness of Nash equilibrium, we will use the contraction mapping method (Cachon and Netessine, 2004), and show in Proposition 5 that

$\left|\partial^{2} M_{2} / \partial c \partial c_{2}\right|<\left|\partial^{2} M_{2} / \partial c^{2}\right|$

and

$\left|\partial^{2} R S_{2} / \partial c \partial c_{2}\right|<\left|\partial^{2} R S_{2} / \partial c_{2}^{2}\right|$.

Proposition 5. There exists a unique Nash equilibrium in the non-cooperative game played between the manufacturer and the risky supplier if the demand distribution is IFR, $u<\left(c_{s}-\tau\right) /\left(c_{2}-\tau\right)$, and $\partial f(x) / \partial x \leqslant 0$ for $x \geqslant R$.

Proof. We first show (43). From (22), we obtain

$\frac{\partial^{2} M_{2}}{\partial c \partial c_{2}}=\frac{\partial R}{\partial c_{2}}+\left(c-c_{s}\right) \frac{\partial^{2} R}{\partial c \partial c_{2}}$.

By (21),

$\frac{\partial^{2} R}{\partial c \partial c_{2}}=\frac{1}{(1-u)(p+\pi-\tau)[f(R)]^{2}} \frac{\partial f(R)}{\partial R} \frac{\partial R}{\partial c_{2}}$.

Combining (45) and (46),

$\frac{\partial^{2} M_{2}}{\partial c \partial c_{2}}=\frac{\partial R}{\partial c_{2}}\left[1+\frac{c-c_{s}}{(1-u)(p+\pi-\tau)[f(R)]^{2}} \frac{\partial f(R)}{\partial R}\right]$.

Using the IFR property, we have

$$
\begin{aligned}
K_{2} & \equiv-\left\{\frac{F_{c}(R)}{[f(R)]^{2}} \frac{\partial f(R)}{\partial R}\right\} \\
& =-\left\{\frac{-(1-u) \tau+c-u c_{2}}{(1-u)(p+\pi-\tau)[f(R)]^{2}} \frac{\partial f(R)}{\partial R}\right\}<1 .
\end{aligned}
$$

We can rewrite (47) as

$\frac{\partial^{2} M_{2}}{\partial c \partial c_{2}}=\frac{\partial R}{\partial c_{2}}\left[1-\frac{\left(c-c_{s}\right) K_{2}}{-(1-u) \tau+c-u c_{2}}\right]$.

Substituting (48) into (24),

$\frac{\partial^{2} M_{2}}{\partial c^{2}}=\frac{\partial R}{\partial c}\left[2-\frac{\left(c-c_{s}\right) K_{2}}{-(1-u) \tau+c-u c_{2}}\right]$.

From (21) and (35),

$\frac{\partial R}{\partial c_{2}}=-u \frac{\partial R}{\partial c}$.

Comparing (49) and (50), and using (51), it follows that

$\left|\partial^{2} M_{2} / \partial c \partial c_{2}\right|<\left|\partial^{2} M_{2} / \partial c^{2}\right|$.

To show (44), we will prove that (cf. Chen et al., 2004)

$\frac{\partial^{2} R S_{2}}{\partial c_{2}^{2}}+\frac{\partial^{2} R S_{2}}{\partial c \partial c_{2}}<0$.

From (5), $\partial S / \partial c=0$. Note that

$\frac{\partial R S_{2}}{\partial c_{2}}+\frac{\partial R S_{2}}{\partial c}=S-R+\left(c_{2}-c_{s 2}\right)\left(\frac{\partial S}{\partial c_{2}}-\frac{\partial R}{\partial c_{2}}-\frac{\partial R}{\partial c}\right)$.

Substituting (51) into (53)

$\frac{\partial R S_{2}}{\partial c_{2}}+\frac{\partial R S_{2}}{\partial c}=S-R+\left(c_{2}-c_{s 2}\right)\left[\frac{\partial S}{\partial c_{2}}+\left(\frac{1-u}{u}\right) \frac{\partial R}{\partial c_{2}}\right]$. 
To show (52), we will demonstrate that the derivative of (54) with respect to $c_{2}$ is negative. Differentiating (54):

$$
\begin{aligned}
& \frac{\partial^{2} R S_{2}}{\partial c_{2}^{2}}+\frac{\partial^{2} R S_{2}}{\partial c \partial c_{2}}=\frac{\partial S}{\partial c_{2}}+\left(c_{2}-c_{s 2}\right) \frac{\partial^{2} S}{\partial c_{2}^{2}}-\frac{\partial R}{\partial c_{2}} \\
& +\left(\frac{1-u}{u}\right)\left(c_{2}-c_{s 2}\right) \frac{\partial^{2} R}{\partial c_{2}^{2}}+\frac{\partial S}{\partial c_{2}}+\left(\frac{1-u}{u}\right) \frac{\partial R}{\partial c_{2}} .
\end{aligned}
$$

Combining (38) and (41),

$\frac{\partial^{2} S}{\partial c_{2}^{2}}=-\frac{K_{1}}{\left(c_{2}-\tau\right)} \frac{\partial S}{\partial c_{2}}$.

Eqs. (37) and (56) and IFR property imply that

$\frac{\partial S}{\partial c_{2}}+\left(c_{2}-c_{s 2}\right) \frac{\partial^{2} S}{\partial c_{2}^{2}}=\frac{\partial S}{\partial c_{2}}\left[1-\frac{\left(c_{2}-c_{s 2}\right) K_{1}}{\left(c_{2}-\tau\right)}\right]<0$.

From (35) and (36),

$$
\begin{aligned}
- & \frac{\partial R}{\partial c_{2}}+\left(\frac{1-u}{u}\right)\left(c_{2}-c_{s 2}\right) \frac{\partial^{2} R}{\partial c_{2}^{2}} \\
& =\frac{u}{(1-u)(p+\pi-\tau) f(R)}\left[-1-\frac{\left(c_{2}-c_{s 2}\right)}{(p+\pi-\tau)[f(R)]^{2}} \frac{\partial f(R)}{\partial R}\right] .
\end{aligned}
$$

Substituting (48) into (58),

$$
\begin{aligned}
- & \frac{\partial R}{\partial c_{2}}+\left(\frac{1-u}{u}\right)\left(c_{2}-c_{s 2}\right) \frac{\partial^{2} R}{\partial c_{2}^{2}} \\
& =\frac{u}{(1-u)(p+\pi-\tau) f(R)}\left[-1+\frac{(1-u)\left(c_{2}-c_{s 2}\right) K_{2}}{-(1-u) \tau+c-u c_{2}}\right]
\end{aligned}
$$

The RHS of (59) is negative if $(1-u)\left(c_{2}-c_{s 2}\right) /[-(1-u)$ $\left.\tau+c-u c_{2}\right]<1$, or equivalently, $u<1+\left[\left(c-c_{2}\right) /\left(c_{s 2}-\tau\right)\right]$. This condition is always satisfied since $c>c_{2}$. Using (35) and (37),

$$
\frac{\partial S}{\partial c_{2}}+\left(\frac{1-u}{u}\right) \frac{\partial R}{\partial c_{2}}=\frac{1}{p+\pi-\tau}\left[\frac{1}{f(R)}-\frac{1}{f(S)}\right] .
$$

The RHS of $(60)$ is nonpositive if $f(S) \leqslant f(R)$. This holds true when $\partial f(x) / \partial x \leqslant 0$ for $x \geqslant R$. Hence, (57), (59), and (60) imply that the RHS of (55) is negative.

Thus, if the manufacturer and the risky supplier are engaged in a pricing game, the manufacturer would charge a higher price than the risky supplier in the resulting Nash equilibrium, and the retailer's ordering policy would be described by (4) and (5). When the conditions stated in Proposition 5 hold, the supply prices $c$ and $c_{2}$ in the Nash equilibrium can be determined by setting the first derivatives (22) and (34) to zero.

\section{Extension to the case where excess demand may be satisfied by an emergency shipment}

In Section 3, it was assumed that the retailer starts the season with inventory from the manufacturer and/or the risky supplier; if demand during the selling season exceeds this starting inventory, excess demand is unsatisfied. In some cases, it may be possible to satisfy all demand during the season by using an emergency supply option, i.e., excess demand is met by backordering. In this section, we outline the extension of our model to this setting. Our problem is different from the variant of the newsvendor problem that was previously studied that assumed certainty in emergency supply (Gallego and Moon, 1993; Khouja, 1996). In our framework, emergency supply corresponds to the risky-supplier alternative which will be available with a probability of $u$, and unavailable with a probability of $1-u$.

The new model follows. The retailer orders $R$ units from the manufacturer, and starts the season with this inventory. If needed, there may be an opportunity to purchase from the risky supplier so that demand in excess of $R$ can be satisfied. If demand is less than $R$, the retailer sells the leftover items at unit salvage price $\tau$.

\subsection{Retailer's problem}

The retailer's expected profit function, $B(R)$, is now given by

$$
\begin{aligned}
B(R)= & (1-u)\left\{p \mathrm{E}[\min (R, X)]+\tau \mathrm{E}(R-X)^{+}\right. \\
& \left.-\pi \mathrm{E}(X-R)^{+}-c R\right\} \\
& +u\left\{p \mu+\tau \mathrm{E}(R-X)^{+}-c_{2} \mathrm{E}(X-R)^{+}-c R\right\} .
\end{aligned}
$$

Differentiating (61) with respect to $R$,

$$
\begin{aligned}
\partial B / \partial R= & (1-u)\left[(p+\pi) F_{c}(R)+\tau F(R)-c\right] \\
& +u\left[\tau F(R)+c_{2} F_{c}(R)-c\right], \\
\partial^{2} B / \partial R^{2}= & -f(R)\left[(p+\pi-\tau)-u\left(p+\pi-c_{2}\right)\right]<0 .
\end{aligned}
$$

The second derivative given in (62) is negative since $\tau<u c_{2}$. We are not interested in the case of $\tau \geqslant u c_{2}$ because there the retailer would only source from the risky supplier. Thus, the first-order condition $\partial B / \partial R=0$ is used for finding the optimal-order quantity, resulting in

$F(R)=\left[p+\pi-c-u\left(p+\pi-c_{2}\right)\right] /\left[p+\pi-\tau-u\left(p+\pi-c_{2}\right)\right]$.

In order to have $R>0$, we need $p+\pi-c-u\left(p+\pi-c_{2}\right)>0$, or equivalently, $c<c_{\max }=(1-u)(p+\pi)+u c_{2}$. At extreme values of $u$, for $u=0$ we have $c_{\max }=p+\pi$, and for $u=1$, $c_{\max }=c_{2}$. Thus, the upper bound on $c$ decreases as the probability that emergency supply will be available $(u)$ increases. Note that in the deterministic emergency supply case (Gallego and Moon, 1993), emergency supply price $c_{2}$ has to be greater than the regular supply price $c$ in order for the model to have a nontrivial solution. However, in our model with random emergency supply, the regular supply price can exceed the emergency supply price.

As in the standard newsvendor model, the RHS of (63) can be interpreted as a ratio of the underage cost to the sum of underage and overage costs. The underage cost is $p+\pi-u(p+\pi)+u c_{2}-c$, and the overage cost is $c-\tau$. If the retailer is short one unit, his profit decreases by an amount equal to the underage cost, and the overage cost measures the impact on the retailer's profit of each item of leftover stock.

In Proposition 6, we show that, for a fixed wholesale price, the manufacturer receives a smaller order when there is an emergency supply. 
Proposition 6. For a given wholesale price $c$, the order received by the manufacturer, $R$, is lower when excess demand is backordered rather than lost.

Proof. Let $R_{1}, R_{2}$, and $R_{3}$ be the value of $R$ satisfying (8), (4), and (63), respectively. The optimal $R$ in the lost sales case is either $R_{1}$ or $R_{2}$, and the optimal $R$ in the backordered demand case is $R_{3}$. Let $Y=u\left(p+\pi-c_{2}\right)$. Then $F\left(R_{3}\right)=(p+\pi-c-Y) /(p+\pi-\tau-Y)$. Comparison with (8) reveals that $R_{1} \geqslant R_{3}$. The numerators on the RHS of (4) and (63) are the same. The denominator on the RHS of (63) is larger than that of (4) if $\tau<c_{2}$. Hence, $R_{2} \geqslant R_{3}$.

If only the risky-supplier source is available, the retailer's expected profit, $B_{\mathrm{es}}$, is

$B_{\mathrm{es}}=u\left(p-c_{2}\right) \mu-(1-u) \pi \mu$.

Note that variability of the demand distribution does not affect the retailer's profit, $B_{\text {es }}$.

\subsection{Manufacturer's problem}

The manufacturer's problem when there is an (stochastic) emergency supply option is

Maximize $M_{3}(c)=\left(c-c_{s}\right) R$

$$
\begin{array}{ll}
\text { subject to } & F(R)=\frac{p+\pi-c-u\left(p+\pi-c_{2}\right)}{p+\pi-\tau-u\left(p+\pi-c_{2}\right)}, \\
& c<(1-u)(p+\pi)+u c_{2}, \\
& B(R) \geqslant 0 .
\end{array}
$$

The unimodality of $M_{3}$ is examined in Proposition 7.

Proposition 7. When excess demand may be satisfied by an emergency shipment, the manufacturer's profit function, $M_{3}$, is quasi-concave in c if the demand distribution is IGFR.

Proof. The proof is similar to the proof of Proposition 1. Using (63),

$\mathrm{d} R / \mathrm{d} c=-\left\{\left[p+\pi-\tau-u\left(p+\pi-c_{2}\right)\right] f(R)\right\}^{-1}<0$,

$\frac{\mathrm{d}^{2} M_{3}}{\mathrm{~d} c^{2}}=\frac{\mathrm{d} R}{\mathrm{~d} c}\left\{2+\frac{\left(c-c_{s}\right)}{\left[p+\pi-\tau-u\left(p+\pi-c_{2}\right)\right][f(R)]^{2}} \frac{\mathrm{d} f(R)}{\mathrm{d} R}\right\}$.

Substituting the first-order condition for $M_{3}$ into (65),

$\frac{\mathrm{d}^{2} M_{3}}{\mathrm{~d} c^{2}}=\frac{\mathrm{d} R}{\mathrm{~d} c}\left[2+\frac{R}{f(R)} \frac{\mathrm{d} f(R)}{\mathrm{d} R}\right]$.

Then, analogous to Proposition 1, it can be shown that $\mathrm{d}^{2} M_{3} / \mathrm{d} c^{2} \leqslant 0$ when $\mathrm{d} M_{3} / \mathrm{d} c=0$.

Thus, the price maximizing $M_{3}$ will be the optimal wholesale price chosen by the manufacturer when an emergency supply source is available to the retailer once demand is known. Let $a^{(3)}$ be the wholesale price satisfying the first-order condition

$\mathrm{d} M_{3} / \mathrm{d} c=R+\left(c-c_{s}\right) \partial R / \partial c=0$,

where $R$ is given by (63). Solving (66),

$a^{(3)}=c_{s}+R\left[p+\pi-\tau-u\left(p+\pi-c_{2}\right)\right] f(R)$.
Hence, the optimal markup in the model with backordered demand is $R\left[p+\pi-\tau-u\left(p+\pi-c_{2}\right)\right] f(R)$. Using (67),

$M_{3}\left(a^{(3)}\right)=\left(a^{(3)}-c_{s}\right) R=R^{2}\left[p+\pi-\tau-u\left(p+\pi-c_{2}\right)\right] f(R)$.

Proposition 8 states that, as in the lost sales case, decreasing supply uncertainty hurts the manufacturer.

Proposition 8. The manufacturer's optimal profit is a nonincreasing function of the probability of emergency supply availability $u$ if the demand distribution is IGFR.

Proof. Using (63), some algebra yields

$$
\begin{aligned}
\mathrm{d} R / \mathrm{d} u= & \left(p+\pi-c_{2}\right)(\tau-c) \\
& \times\left[p+\pi-\tau-u\left(p+\pi-c_{2}\right)\right]^{-2}[f(R)]^{-1}<0 .
\end{aligned}
$$

Substituting $g(R)=\left[f(R) R / F_{c}(R)\right]$, we can rewrite (68) as

$M_{3}\left(a^{(3)}\right)=g(R) R(c-\tau)$.

Following the same steps as in Proposition 3,

$\frac{\mathrm{d} M_{3}\left(a^{(3)}\right)}{\mathrm{d} u}=(c-\tau) \frac{\partial R}{\partial u}\left[R \frac{\partial g(R)}{\partial R}+g(R)\right] \leqslant 0$.

By (69), and the assumption that $c>\tau$, the left-hand side (LHS) of (71) is nonpositive. Thus, the manufacturer's optimal profit is a nonincreasing function of $u$.

It can be shown that an increase in $c_{2}$ will never cause the manufacturer's profit to decrease. Using (63),

$\mathrm{d} R / \mathrm{d} c_{2}=u(c-\tau)\left[p+\pi-\tau-u\left(p+\pi-c_{2}\right)\right]^{-2}[f(R)]^{-1}>0$.

Differentiating (70)

$\frac{\mathrm{d} M_{3}\left(a^{(3)}\right)}{\mathrm{d} c_{2}}=(c-\tau) \frac{\partial R}{\partial c_{2}}\left[R \frac{\partial g(R)}{\partial R}+g(R)\right] \geqslant 0$.

Thus, the manufacturer's optimal profit is a nondecreasing function of the emergency supply price $c_{2}$, if the demand distribution is IGFR.

We now turn our attention to the behavior of the optimal wholesale price as the emergency supply characteristics change. First we rewrite (67) as

$a^{(3)}=c_{s}+(c-\tau) g(R)$.

Using (74), we obtain

$\frac{\mathrm{d} a^{(3)}}{\mathrm{d} u}=(c-\tau) \frac{\partial g(R)}{\partial R} \frac{\partial R}{\partial u} \leqslant 0$.

The sign of the LHS of (75) is based on arguments similar to those in Proposition 8. Hence, the manufacturer's optimal wholesale price is a nonincreasing function of the probability of emergency supply availability $u$ if the demand distribution is IGFR. Finally, we look into the impact of $c_{2}$ on $c^{*}$. From (74):

$\frac{\mathrm{d} a^{(3)}}{\mathrm{d} c_{2}}=(c-\tau) \frac{\partial g(R)}{\partial R} \frac{\partial R}{\partial c_{2}} \geqslant 0$.

By (72) and the IGFR assumption, the LHS of (76) is nonnegative. Thus, increases in emergency supply uncertainty or price will never result in a decrease in the manufacturer's optimal wholesale price if the demand distribution is IGFR. 


\section{Extension to the case where order cancellation is allowed}

In certain cases, the manufacturers allow their customers to revise their order quantities in exchange for a penalty payment (e.g., Xu, 2005). Suppose the retailer can cancel any portion of his order from the manufacturer after assessing the availability of the risky supplier, and before the start of the season. Let $r$ be the refund per unit that the retailer receives if he decides to cancel any desired portion of his initial order $R, r<c$. Also, let $S$ be the total stocking level after any cancellation of the initial order and ordering from the risky supplier. The ability to cancel the order does not make the retailer worse off compared to the case where cancellation is not possible. Thus, if $c \leqslant c_{2}$, the risky supplier will not be given a positive order, as in the previous model. Clearly, if $r \leqslant c_{2}$, the risky supplier will definitely not be used, and there is no need to modify the initial order $R$. Cancellation might occur only when $c>r>c_{2}$, so we focus on that case. If the risky supplier is available, then the optimal policy is to cancel all of $R$, and source fully from the risky supplier. Hence, the retailer's objective function can be written as

$$
\begin{aligned}
B(R, S)= & (1-u)\{p \mathrm{E}[\min (R, X)] \\
& \left.+\tau \mathrm{E}(R-X)^{+}-\pi \mathrm{E}(X-R)^{+}-c R\right\} \\
& +u\left\{p \mathrm{E}[\min (S, X)]+\tau \mathrm{E}(S-X)^{+}\right. \\
& \left.-\pi \mathrm{E}(X-S)^{+}-c_{2} S+(r-c) R\right\} .
\end{aligned}
$$

The first-order conditions lead to

$$
F(R)=[(1-u)(p+\pi-c)+u(r-c)] /[(1-u)(p+\pi-\tau)],
$$

$F(S)=\left(p+\pi-c_{2}\right) /(p+\pi-\tau)$.

Since $B(R, S)$ is concave, the optimal solution is given by (78) and (79). Comparing (78) with (4), since $r>c_{2}$, the initial order from the manufacturer, $R$ is higher when cancellation is possible.

\section{Optimal ordering policy when demand is price- dependent}

In this section we analyze the retailer's problem with lost sales when demand for the product is dependent on selling price. The newsvendor problem with price-dependent demand has been studied using either an additive or multiplicative uncertainty approach (e.g., Petruzzi and Dada, 1999; Choi, 2007; Arcelus et al., 2007; Karakul, 2008; Webster and Weng, 2008). We consider that randomness in demand is incorporated into the model in an additive form. Thus, the random demand during the season, $X$, equals

$X(p, \varepsilon)=y(p)+\varepsilon$,

where $y(p)$ describes the functional relationship between demand and price, and $\varepsilon$ is a random variable. More specifically, we use the linear relationship $y(p)=$ $a-b p(a>0, b>0)$. In the additive error approach, the variance of the demand does not depend on the price. We also let $e(\cdot)$ represent the probability density function of $\varepsilon$. Further, let $m$ and $v$ denote the mean and standard deviation of $\varepsilon$, respectively.
The retailer's ordering problem is deconstructed into two stages. In the first stage, the retailer places an order of $R$ units with the manufacturer. After ascertaining the availability of the risky supplier, the retailer orders $S-R$ units from the risky supplier (if available). Then, given the available stock on hand, the retailer sets the selling price $p$ and the season starts. Since it is uncertain whether the risky source will be used, the optimal price should be determined contingent on the availability of the risky supplier.

\subsection{Deterministic demand}

Let $i \in\{1,2\}$ be the state of supplier availability, with $i=1$ indicating that the risky supplier is available. As in earlier sections, we assume the probability that $i=1$ is $u$. Let $p_{i}$ be the selling price in state $i$, with $i=1,2$. First we consider the case of deterministic demand. Since the risky supplier will be used only if $c_{2}<c$, we make that assumption. If there were only the reliable manufacturer available to the retailer in the problem, the retailer would maximize his profit $(p-c)(a+m-b p)$, which leads to the optimal price $(a+m+b c)$ $2 b$, and the optimal-order amount $R^{\mathrm{u}}=(a+m-b c) / 2$. Clearly, $R^{\mathrm{u}}$ is an upper bound on the optimal $R$ in the problem including the risky supplier. If $R$ units are ordered earlier, and state 2 is observed, i.e., the risky supplier is not available, the optimal price, $p_{2}^{*}=(a+m-R) / b$. If the risky supplier is available, the optimal price $p_{1}^{*}=\left(a+m+b c_{2}\right) / 2 b$, and the optimal total stocking level $S^{*}=a-b p_{1}^{*}+m=\left(a+m-b c_{2}\right) / 2$. Thus, the retailer's expected profit is written as

$$
\begin{aligned}
B(R)= & u\left[p_{1}^{*}\left(a-b p_{1}^{*}+m\right)-c_{2}\left(a-b p_{1}^{*}+m-R\right)-c R\right] \\
& +(1-u)\left[\left(p_{2}^{*}-c\right) R\right] .
\end{aligned}
$$

We can show that

$\left(p_{1}^{*}-c_{2}\right)\left(a-b p_{1}^{*}+m\right)=\left(a+m-b c_{2}\right)^{2} / 4 b$.

From (80), we have

$\partial B / \partial R=u\left(c_{2}-c\right)+(1-u)[(a+m-2 R) / b-c]$,

$\partial^{2} B / \partial R^{2}=-2(1-u) / b \leqslant 0$.

Thus, $B(R)$ is concave in $R$, and the optimal amount to be ordered from the reliable manufacturer $R^{*}$ can be found by setting (81) to zero:

$R^{*}=0.5\left[(a+m-b c)+u b\left(c_{2}-c\right) /(1-u)\right]$.

If the RHS of (82) is negative, the optimal $R$ is zero. Using (82), we can show that $\partial R^{*} / \partial u \leqslant 0, \partial R^{*} / \partial c \leqslant 0$, and $\partial R^{*} /$ $\partial c_{2} \geqslant 0$. If $R$ is zero, the retailer's optimal expected profit from (80) is

$B(R=0)=u\left(a-b c_{2}\right)^{2} / 4 b$.

\subsection{Stochastic demand}

We now return to the stochastic demand case. The retailer's expected profit function in state 1 is

$$
\begin{aligned}
B_{1}\left(p_{1}, S \mid R\right)= & p_{1} \mathrm{E}[\min (S, X)]+\tau \mathrm{E}(S-X)^{+} \\
& -\pi \mathrm{E}(X-S)^{+}-c R-c_{2}(S-R),
\end{aligned}
$$


where $S \geqslant R$ is the total stocking level. Let $p_{1}^{*}$ and $S^{*}$ be the optimal decisions maximizing (83) for a given $R$. The retailer's expected profit in state 2 is

$B_{2}\left(p_{2} \mid R\right)=p_{2} \mathrm{E}[\min (R, X)]+\tau \mathrm{E}(R-X)^{+}-\pi \mathrm{E}(X-R)^{+}-c R$.

Denoting the optimal price in state 2 by $p_{2}^{*}$, the optimal amount to purchase from the manufacturer, $R^{*}$, is found by maximizing

$$
\begin{aligned}
B(R)= & u\left\{p_{1}^{*}(R) \mathrm{E}\left[\min \left(S^{*}(R), X\right)\right]\right. \\
& +\tau \mathrm{E}\left[S^{*}(R)-X\right]^{+}-\pi \mathrm{E}\left[X-S^{*}(R)\right]^{+}-c R \\
& \left.-c_{2}\left[S^{*}(R)-R\right]\right\}+(1-u)\left\{p_{2}^{*}(R) \mathrm{E}[\min (R, X)]\right. \\
& \left.+\tau \mathrm{E}(R-X)^{+}-\pi \mathrm{E}(X-R)^{+}-c R\right\} .
\end{aligned}
$$

Let

$\Lambda(z)=\int_{0}^{z}(z-\varepsilon) e(\varepsilon) \mathrm{d} \varepsilon, \quad \Theta(z)=\int_{z}^{\infty}(\varepsilon-z) e(\varepsilon) \mathrm{d} \varepsilon$.

Then we can rewrite (83) as

$$
\begin{aligned}
B_{1}\left(p_{1}, z_{S} \mid R\right)= & p_{1}\left[y\left(p_{1}\right)+m-\Theta\left(z_{S}\right)\right]+\tau \Lambda\left(z_{S}\right) \\
& -\pi \Theta\left(z_{S}\right)-c R-c_{2}\left[y\left(p_{1}\right)+z_{S}-R\right],
\end{aligned}
$$

where $z_{S}=S-y\left(p_{1}\right)$. Note that $\Lambda\left(z_{S}\right)$ gives expected leftovers, and $\Theta\left(z_{S}\right)$ reflects expected shortages. If $y\left(p_{1}\right)+z_{S} \leqslant R$, no purchase from the risky supplier is made. Therefore, we need to take into account only those combinations of $p_{1}$ and $z_{S}$ that satisfy $y\left(p_{1}\right)+z_{S}>R$.

Differentiating (86), we have

$\partial B_{1} / \partial p_{1}=a+m-2 b p_{1}+b c_{2}-\Theta\left(z_{S}\right)$

Thus, for a given $z_{S}, B_{1}(\cdot)$ is maximized when (cf. Petruzzi and Dada, 1999)

$p_{1}=p_{1}^{*}=\left[a+m+b c_{2}-\Theta\left(z_{S}\right)\right] / 2 b$.

Hence, the retailer's problem when $i=1$ is solved in two steps using a line search algorithm. First, the optimal price is found for a given $S$ (and $R$ ) by (88). Then a search over $z_{S}$ is conducted to find the best pair $\left(p_{1}^{*}, z_{S}{ }^{*}\right)$ maximizing (86).

Let $z_{R}=R-y\left(p_{2}\right)$. If the risky supplier is not available, i.e., $i=2$, the retailer's expected profit function is

$$
\begin{aligned}
B_{2}\left(p_{2} \mid z_{R}\right)= & p_{2}\left[y\left(p_{2}\right)+m-\Theta\left(z_{R}\right)\right] \\
& +\tau \Lambda\left(z_{R}\right)-\pi \Theta\left(z_{R}\right)-c\left[y\left(p_{2}\right)+z_{R}\right] .
\end{aligned}
$$

The optimal price, $p_{2}^{*}$, is determined as

$$
p_{2}^{*}=\left[a+m+b c-\Theta\left(z_{R}\right)\right] / 2 b .
$$

Finally we substitute $p_{1}^{*}(R), p_{2}^{*}(R)$, and $S^{*}(R)$ into (85) and obtain $R^{*}$. The optimal amount ordered from the risky supplier $S-R$ can be positive only when $c_{2}<c$. In terms of $z_{S}$ and $z_{R}$, the retailer's expected profit (85) can be written as

$$
\begin{aligned}
B\left(z_{S}, z_{R}\right)= & u\left\{p_{1}^{*}\left(z_{S}\right)\left[y\left(p_{1}^{*}\left(z_{S}\right)\right)+m-\Theta\left(z_{S}\right)\right]+\tau \Lambda\left(z_{S}\right)\right. \\
& -\pi \Theta\left(z_{S}\right)-c\left[y\left(p_{2}^{*}\left(z_{R}\right)\right)+z_{R}\right]-c_{2}\left[y\left(p_{1}^{*}\left(z_{S}\right)\right)+z_{S}\right. \\
& \left.\left.-y\left(p_{2}^{*}\left(z_{R}\right)\right)-z_{R}\right]\right\}+(1-u)\left\{p _ { 2 } ^ { * } ( z _ { R } ) \left[y\left(p_{2}^{*}\left(z_{R}\right)\right)\right.\right. \\
& \left.+m-\Theta\left(z_{R}\right)\right]+\tau \Lambda\left(z_{R}\right)-\pi \Theta\left(z_{R}\right) \\
& \left.-c\left[y\left(p_{2}^{*}\left(z_{R}\right)\right)+z_{R}\right]\right\} .
\end{aligned}
$$

We remark that using an analogous procedure, the optimal ordering and pricing policy in the model involving multiplicative uncertainty can be determined.

\section{Optimal ordering policy when supply availability depends on demand}

As noted earlier, the Bernoulli parameter representing the probability of supplier availability may itself be uncertain. Further, it can also be correlated with demand for the product. For example, demand and the probability of supply availability may be inversely related to each other because the total supply capacity in the market may be insufficient relative to demand when expected demand is high. We now analyze the retailer's problem when demand $X$ and the probability of supply availability $U$ are interdependent. Let $h(x, u)$ be the joint pdf of $X$ and $U$. The retailer's expected profit can be written as

$$
\begin{aligned}
& B(R, S)=p \int_{0}^{1} \int_{0}^{R}(1-u) x h(x, u) \mathrm{d} x \mathrm{~d} u+p R \int_{0}^{1} \int_{R}^{\infty}(1-u) h(x, u) \mathrm{d} x \mathrm{~d} u \\
& \quad+\tau \int_{0}^{1} \int_{0}^{R}(1-u)(R-x) h(x, u) \mathrm{d} x \mathrm{~d} u \\
& \quad-\pi \int_{0}^{1} \int_{R}^{\infty}(1-u)(x-R) h(x, u) \mathrm{d} x \mathrm{~d} u \\
& +p \int_{0}^{1} \int_{0}^{S} u x h(x, u) \mathrm{d} x \mathrm{~d} u+p S \int_{0}^{1} \int_{S}^{\infty} u h(x, u) \mathrm{d} x \mathrm{~d} u \\
& +\tau \int_{0}^{1} \int_{0}^{S} u(S-x) h(x, u) \mathrm{d} x \mathrm{~d} u \\
& -\pi \int_{0}^{1} \int_{S}^{\infty} u(x-S) h(x, u) \mathrm{d} x \mathrm{~d} u-c_{2}(S-R) \int_{0}^{1} u w(u) \mathrm{d} u-c R .
\end{aligned}
$$

Differentiating (92), we have

$$
\begin{aligned}
\partial B / \partial R= & (p+\pi) F_{c}(R)+\tau F(R)-c-p \int_{0}^{1} \int_{R}^{\infty} u h(x, u) \mathrm{d} x \mathrm{~d} u \\
& -\tau \int_{0}^{1} \int_{0}^{R} u h(x, u) \mathrm{d} x \mathrm{~d} u-\pi \int_{0}^{1} \int_{R}^{\infty} u h(x, u) \mathrm{d} x \mathrm{~d} u+c_{2} \mathrm{E}(U) .
\end{aligned}
$$

$$
\begin{aligned}
\partial B / \partial S= & p \int_{0}^{1} \int_{S}^{\infty} u h(x, u) \mathrm{d} x \mathrm{~d} u+\tau \int_{0}^{1} \int_{0}^{S} u h(x, u) \mathrm{d} x \mathrm{~d} u \\
& +\pi \int_{0}^{1} \int_{S}^{\infty} u h(x, u) \mathrm{d} x \mathrm{~d} u-c_{2} \mathrm{E}(U)
\end{aligned}
$$

Using (93) and (94),

$\partial^{2} B / \partial R^{2}=-(p+\pi-\tau) f(R)+(p+\pi-\tau) \int_{0}^{1} u h(R, u) \mathrm{d} u<0$,

since $f(R)=\int_{0}^{1} h(R, u) \mathrm{d} u>\int_{0}^{1} u h(R, u) \mathrm{d} u$,

$\partial^{2} B / \partial S^{2}=-(p+\pi-\tau) \int_{0}^{1} u h(S, u) \mathrm{d} u<0$.

Thus, the retailer's objective function is concave in $R$ and $S$; consequently, if the retailer uses both suppliers in the optimal solution, the optimal $R$ and $S$ can be found by setting (93) and (94) to zero.

\section{Numerical examples}

In this section we present some numerical examples. We assume that retail demand for the product is normally distributed given that it is a frequently used demand distribution in the inventory literature.

In our numerical study we use the following set of values for the parameters: $p=20, \pi=\tau=3, c_{s}=5$, 
$c_{2} \in\{8,12\}, \mu=100, \sigma \in\{20,40\}$, and $u \in\{0.2,0.5\}$. For the model in which excess demand is lost, Table 2 gives the optimal wholesale price for the manufacturer, $c^{*}$, and resulting values of parameters associated with the retailer's purchasing policy, $R$ and $S$. We use $B$ to denote the retailer's expected profit, and $M$ to denote the manufacturer's profit. Table 3 shows the results for the model with the emergency supply option.

As the results in Tables 2 and 3 indicate, the manufacturer's profit decreases as $u$ increases. This pattern is in accordance with Propositions 3 and 8 . Hence, the risky supplier's proportion of the retailer's purchasing plan is higher when there is less supply uncertainty, as evidenced by the decrease in the manufacturer's profit $M$. Because of the reduction in the probability of using the cheaper source, higher supply uncertainty decreases the retailer's expected profit. Confirming the analytical study, a lower level of supply uncertainty exerts a downward pressure on the manufacturer price $c^{*}$.

As expected, a higher $c_{2}$ reduces the retailer's expected profit while positively influencing the manufacturer's profit. Similarly, the manufacturer's optimal price $c^{*}$ increases as $c_{2}$ increases. We remark that the total profit of the manufacturer and the risky supplier depends on $c_{2}$. As $c_{2}$ decreases, the manufacturer will have to select a lower price and her profit will decrease.

Comparing results for $\sigma=20$ against $\sigma=40$, we see that higher demand variability leads to higher retailer profit with a concomitant reduction in the manufacturer's profit. The decrease in the manufacturer's profit appears to be mainly related to the decrease in the optimal price $c^{*}$

Table 2

Optimal profits of the retailer and the manufacturer (lost sales model)

\begin{tabular}{rrrrrrrr}
\hline$c_{2}$ & $u$ & $\sigma$ & $c^{*}$ & $R$ & $S$ & \multicolumn{1}{l}{$B$} & \multicolumn{1}{l}{$M$} \\
\hline 8 & 0.2 & 20 & 17.9 & 77.6 & 113.5 & 116.4 & 1000.9 \\
& & 40 & 15.5 & 76.8 & 127.0 & 183.3 & 806.8 \\
& 0.5 & 20 & 14.0 & 79.3 & 113.5 & 489.8 & 713.4 \\
& & 40 & 12.3 & 81.3 & 127.0 & 499.8 & 593.4 \\
& & & & & & & \\
12 & 0.2 & 20 & 18.6 & 78.2 & 102.5 & 38.0 & 1063.1 \\
& & 40 & 16.0 & 79.0 & 105.0 & 114.1 & 869.3 \\
& 0.5 & 20 & 15.7 & 81.7 & 102.5 & 298.4 & 874.1 \\
& & 40 & 13.6 & 88.8 & 105.0 & 328.2 & 763.9 \\
\hline
\end{tabular}

Table 3

Optimal profits of the retailer and the manufacturer in the model with an emergency supply option

\begin{tabular}{|c|c|c|c|c|c|c|}
\hline$c_{2}$ & $u$ & $\sigma$ & $c^{*}$ & $R$ & $B$ & $M$ \\
\hline \multirow[t]{4}{*}{8} & \multirow[t]{2}{*}{0.2} & 20 & 18.0 & 76.3 & 118.0 & 991.4 \\
\hline & & 40 & 15.5 & 74.8 & 208.4 & 785.9 \\
\hline & \multirow[t]{2}{*}{0.5} & 20 & 14.1 & 75.7 & 504.3 & 688.7 \\
\hline & & 40 & 12.3 & 73.8 & 560.5 & 538.5 \\
\hline \multirow[t]{4}{*}{12} & \multirow[t]{2}{*}{0.2} & 20 & 18.7 & 76.3 & 44.7 & 1045.3 \\
\hline & & 40 & 16.0 & 75.4 & 146.0 & 829.9 \\
\hline & \multirow[t]{2}{*}{0.5} & 20 & 15.8 & 76.2 & 325.5 & 823.2 \\
\hline & & 40 & 13.7 & 74.5 & 393.4 & 648.3 \\
\hline
\end{tabular}

rather than to the change in the order amount $R$. In Table 2, when demand variability increases, at a low riskysupplier price $c_{2}$, the amount ordered from the manufacturer may decrease. However, when $c_{2}$ is high, the order placed with the manufacturer seems to increase as demand variability increases. In the emergency supply case (Table 3 ), demand variance exerts a negative impact on both $c^{*}$ and $R$.

Lau et al. (2001) investigated a problem in which a manufacturer, acting as a Stackelberg leader, sets the supply price to which the retailer responds with an order amount. They found that in this scenario with normally distributed demand, as demand variance increases, the retailer's expected profit increases, but after a threshold point, further increase in demand variance decreases the retailer's expected profit. Although not shown in Tables 2 and 3 , we have observed a similar impact of demand variance on retailer's profit in our problem.

When results in Tables 2 and 3 are compared for a given set of parameters, the optimal wholesale price $c^{*}$ appears fairly stable regardless of whether excess demand is lost or backordered. Due to this behavior of $c^{*}$, the quantity ordered from the manufacturer, $R$, is less when the retailer can prevent lost sales via emergency supply (Proposition 6). The retailer's expected profit is higher when there is emergency supply. The improvement in expected profit compared to the lost sales case is especially significant when demand variance is high. The manufacturer experiences a reduction in her profit when excess demand is backordered. The retailer decreases the amount ordered from the manufacturer when there is a chance to order from the risky supplier after observing demand.

The amount ordered from the manufacturer $R$ shows little variation with changes in $c_{2}, u$, and $\sigma$ in Table 3. We can interpret this result as an indication of the existence of a target sale amount for the manufacturer independent of these parameters when an emergency supply option is available to the retailer. We also noticed that when supply risk is high, $R$ is fairly robust to changes in demand variability, with or without backordered demand. Note that the patterns observed in our study are associated with intermediate values of $u$ and $c_{2}$. As $c_{2}$ decreases to a very low level, the optimal $R$ in response to the optimal manufacturer price may decrease.

Finally, we present numerical examples for the pricedependent demand scenario. We use the additive linear demand model with following values of parameters: $a=200, \quad b=8, \quad m=0, \quad \pi=\tau=3, \quad v \in\{20,40\}, \quad$ and $u \in\{0.2,0.5\}$. We assume $\varepsilon$ is normally distributed. The optimal stocking level and prices, and the retailer's maximal expected profit are listed in Table 4 . The results indicate that when $c=c_{2}$, the retailer decides to source fully from the manufacturer, and does not use the risky supplier even if he is available in the second stage. Given $c_{2}<c$, the retailer allocates an increasing share of his order to the risky supplier as the probability of availability $u$ increases. The retailer's profit decreases with demand variance. When there is a low probability of availability, the decrease in the retailer's profit is not significant as $c_{2}$ increases from 8 to 12. As in Tables 2 and 3, the retailer's 
Table 4

Retailer's optimal ordering policy under price-dependent demand

\begin{tabular}{lrrlllllr}
\hline$u$ & $v$ & $c_{2}$ & $c$ & $p_{1}^{*}$ & $p_{2}^{*}$ & $R$ & $S$ & \multicolumn{1}{l}{$B$} \\
\hline 0.2 & 20 & 8 & 12 & 16.3 & 17.9 & 54.5 & 80.0 & 202.4 \\
& & 12 & 12 & 18.0 & 18.0 & 56.0 & 56.0 & 192.4 \\
& 40 & 8 & 12 & 16.0 & 17.3 & 55.6 & 92.0 & 65.0 \\
& & 12 & 12 & 17.4 & 17.4 & 58.5 & 58.5 & 50.9 \\
& & & & & & & & \\
0.5 & 20 & 8 & 12 & 16.3 & 17.7 & 50.3 & 80.0 & 221.9 \\
& & 12 & 12 & 18.0 & 18.0 & 56.0 & 56.0 & 192.4 \\
& 40 & 8 & 12 & 16.0 & 16.8 & 46.0 & 92.0 & 95.8 \\
& & 12 & 12 & 17.4 & 17.4 & 58.5 & 58.5 & 50.9 \\
\hline
\end{tabular}

profit increases as the probability of risky-supplier availability increases.

\section{Conclusion}

We studied the extension of the basic single-period (newsvendor) model in the case where future supply is randomly available, and the retailer can mitigate his procurement risk by making an advance purchase commitment. After analyzing the retailer's ordering problem, we solved the manufacturer's pricing problem by assuming the manufacturer is the Stackelberg leader. We derived the conditions ensuring unimodality of the manufacturer's objective function. Both the lost sales and backordered demand cases were investigated. Using numerical examples, we explored the impact of various parameters - demand variability, and the price and availability of the risky supplier-on the optimal decisions of the retailer and the manufacturer. It was also shown that, under certain conditions on the demand distribution and the probability of supply availability, there exists a unique Nash equilibrium in the competitive pricing game involving the manufacturer and the risky supplier. We also investigated the retailer's problem when (i) it is possible to cancel any portion of the initial order, (ii) demand for the product is sensitive to the selling price, and (iii) supply availability and demand for the product are statistically dependent.

The well-known newsvendor model provides a useful framework for analyzing the tradeoffs between holding costs and shortage costs incurred by a retailer facing uncertain demand. In this paper we analyzed the effect of supply uncertainty from the perspective of both the retailer and the manufacturer, and found that in a Stackelberg game led by the manufacturer, the retailer is expected to earn a higher profit when excess demand is backordered rather than lost. When excess demand is backordered, the order quantity committed by the retailer in advance stays within a narrow band across varying degrees of demand and supply uncertainties. The manufacturer's optimal wholesale price was relatively insensitive to the modeling assumption of lost sales or backordering. Future research could incorporate some of the other specifications of supply uncertainty discussed in the literature.

\section{Acknowledgment}

The author is grateful to an anonymous referee for his/her helpful suggestions, which have significantly improved the paper.

\section{References}

Abdel-Malek, L., Montanari, R., Meneghetti, D., 2008. The capacitated newsboy problem with random yield: The gardener problem. International Journal of Production Economics 115, 113-127.

Agrawal, N., Nahmias, S., 1997. Rationalization of the supplier base in the presence of yield uncertainty. Production and Operations Management 6, 291-308.

Arcelus, F.J., Kumar, S., Srinivasan, G., 2007. Pricing and rebate policies for the newsvendor problem in the presence of a stochastic redemption rate. International Journal of Production Economics 107, 467-482.

Babich, V., Burnetas, A.N., Ritchken, P.H., 2007. Competition and diversification effects in supply chains with supplier default risk. Manufacturing \& Service Operations Management 9, 123-146.

Cachon, G.P., Netessine, S., 2004. Game theory in supply chain analysis. In: Simchi-Levi, D., Wu, D.W., Shen, Z.-J. (Eds.), Handbook of Quantitative Supply Chain Analysis: Modeling in the E-Business Era. Kluwer, Dordrecht.

Chen, F.Y., Yan, H., Yao, L., 2004. A newsvendor pricing game. IEEE Transactions on Systems, Man and Cybernetics_Part A: Systems and Humans 34, 450-456.

Choi, T.M., 2007. Pre-season stocking and pricing decisions for fashion retailers with multiple information updating. International Journal of Production Economics 106, 146-170.

Ciarallo, F.W., Akella, R., Morton, T.E., 1994. A periodic review, production planning model with uncertain capacity and uncertain demand-Optimality of extended myopic policies. Management Science 40, 320-332.

Dada, M., Petruzzi, N.C., Schwarz, L.B., 2007. A newsvendor's procurement problem when suppliers are unreliable. Manufacturing \& Service Operations Management 9, 9-32.

Eppen, G.D., Iyer, A.V., 1997. Backup agreements in fashion buying-The value of upstream flexibility. Management Science 43, 1469-1484.

Erdem, A.S., Ozekici, S., 2002. Inventory models with random yield in a random environment. International Journal of Production Economics 78, 239-253.

Erdem, A.S., Fadiloglu, M.M., Ozekici, S., 2006. An EOQ model with multiple suppliers and random capacity. Naval Research Logistics 53, $101-114$.

Gallego, G., Moon, I., 1993. The distribution-free newsboy problem: Review and extensions. Journal of the Operational Research Society 44, 825-834.

Gullu, R., Onol, E., Erkip, N., 1999. Analysis of an inventory system under supply uncertainty. International Journal of Production Economics 59, 377-385.

Gurler, U., Parlar, M., 1997. An inventory problem with two randomly available suppliers. Operations Research 45, 904-918.

Inderfurth, K., 2008. How to protect against demand and yield risks in MRP systems. International Journal of Production Economics, in press, doi:10.1016/j.ijpe.2007.02.005.

Jain, K., Silver, E.A., 1995. The single-period procurement problem where dedicated supplier capacity can be reserved. Naval Research Logistics 42, 915-934.

Juttner, U., 2005. Supply chain risk management: Understanding the business requirements from a practitioner perspective. International Journal of Logistics Management 16, 120-141.

Karakul, M., 2008. Joint pricing and procurement of fashion products in the existence of clearance markets. International Journal of Production Economics 114, 487-506.

Kharif, O., 2003. Motorola's fuzzy camera-phone picture. Business Week December.

Khouja, M., 1996. A note on the newsboy problem with an emergency supply option. Journal of the Operational Research Society 47, 1530-1534.

Khouja, M., 1999. The single-period (news-vendor) problem: Literature review and suggestions for future research. Omega-International Journal of Management Science 27, 537-553.

Lariviere, M.A., Porteus, E.L., 2001. Selling to the newsvendor: An analysis of price-only contracts. Manufacturing \& Service Operations Management 3, 293-305. 
Lau, H.-S., Lau, A.H.-L., Kottas, J.F., 2001. Pricing/inventory decisions and profit shares in a non-integrated marketing channel for a singleperiod product. Journal of the Operational Research Society 52, 682-690.

Minner, S., 2003. Multiple supplier inventory models in supply chain management: A review. International Journal of Production Economics 81-82, 265-279.

Mohebbi, E., 2004. A replenishment model for the supply-uncertainty problem. International Journal of Production Economics 87, 25-37.

Mohebbi, E., Hao, D., 2006. When supplier's availability affects the replenishment lead time-An extension of the supply-interruption problem. European Journal of Operational Research 175, 992-1008.

Norrman, A., Jansson, U., 2004. Ericsson's proactive supply chain risk management approach after a serious sub-supplier accident. International Journal of Physical Distribution \& Logistics Management 34 434-456.

Ozekici, S., Parlar, M., 1999. Inventory models with unreliable suppliers in random environment. Annals of Operations Research 91, 123-136.

Parlar, M., 1997. Continuous review inventory problem with random supply interruptions. European Journal of Operational Research 99, 366-385.

Parlar, M., Wang, Y., Gerchak, Y., 1995. A periodic review inventory model with Markovian supply availability. International Journal of Production Economics 42, 131-136.
Petruzzi, N.C., Dada, M., 1999. Pricing and the newsvendor problem: A review with extensions. Operations Research 47, 183-194.

Serel, D.A., 2007. Capacity reservation under supply uncertainty. Computers \& Operations Research 34, 1192-1220.

Serel, D.A., Dada, M., Moskowitz, H., 2001. Sourcing decisions with capacity reservation contracts. European Journal of Operational Research 131, 635-648.

Sethi, S.P., Yan, H., Zhang, H., 2005. Analysis of a duopoly supply chain and its application in electricity spot markets. Annals of Operations Research 135, 239-259.

Silver, E.A., Pyke, D.F., Peterson, R., 1998. Inventory Management and Production Planning and Scheduling, third ed. Wiley, New York.

Waller, D.L., 2003. Operations Management: A Supply Chain Approach, second ed. Thomson, London.

Wang, Y., Gerchak, Y., 1996. Periodic review production models with variable capacity, random yield, and uncertain demand. Management Science 42, 130-137.

Webster, S., Weng, Z.K., 2008. Ordering and pricing policies in a manufacturing and distribution supply chain for fashion products. International Journal of Production Economics 114, 476-486.

$\mathrm{Xu}, \mathrm{N}$., 2005. Multi-period dynamic supply contracts with cancellation. Computers \& Operations Research 32, 3129-3142.

Yang, S., Yang, J., Abdel-Malek, L., 2007. Sourcing with random yields and stochastic demand: A newsvendor approach. Computers \& Operations Research 34, 3682-3690. 